\title{
A prospective epidemiological study of injuries in four English professional football clubs
}

\author{
Richard D Hawkins, Colin W Fuller
}

\begin{abstract}
Objective-To define the causes of injuries to players in English professional football during competition and training.

Method-Lost time injuries to professional and youth players were prospectively recorded by physiotherapists at four English League clubs over the period 1994 to 1997. Data recorded included information related to the injury, date and place of occurrence, type of activity, and extrinsic playing factors.

Results-In all, 67\% of all injuries occurred during competition. The overall injury frequency rate (IFR) was 8.5 injuries/1000 hours, with the IFR during competition (27.7) being significantly $(\mathrm{p}<0.01)$ higher than that during training (3.5). The IFRs for youth players were found to increase over the second half of the season, whereas they decreased for professional players. There were no significant differences in IFRs for professional and youth players during training. There were significantly $(p<0.01)$ more injuries in competition in the 15 minute periods at the end of each half. Strains $(41 \%)$, sprains $(20 \%)$, and contusions $(20 \%)$ represented the major types of injury. The thigh $(23 \%)$, ankle $(17 \%)$, knee $(14 \%)$, and lower leg (13\%) represented the major locations of injury, with significantly $(p<0.01)$ more injuries to the dominant body side. Reinjury accounted for $22 \%$ of all injuries. Only $12 \%$ of all injuries were caused by a breach of the rules of football, although player to player contact was involved in $41 \%$ of all injuries.
\end{abstract}

Conclusions-The overall level of injury to professional footballers has been shown to be around 1000 times higher than for industrial occupations generally regarded as high risk. The high level of muscle strains, in particular, indicates possible weaknesses in fitness training programmes and use of warming up and cooling down procedures by clubs and the need for benchmarking players' levels of fitness and performance. Increasing levels of injury to youth players as a season progresses emphasises the importance of controlling the exposure of young players to high levels of competition.

(Br F Sports Med 1999;33:196-203)

Keywords: football; injury; risk factors

Football players are known to suffer relatively high rates of injury compared with participants in other sports and other occupations..$^{1-7}$ It is therefore important, and a legal requirement, for managers of professional football clubs to reduce this level of risk wherever possible to ensure, so far as is reasonably practicable, the health and safety of their players. ${ }^{8}$ To assist with this process, Fuller and Hawkins ${ }^{9}$ have discussed the benefits of introducing health surveillance procedures to provide clubs with benchmark profiles of their players' current and potential fitness levels as part of an overall injury prevention and rehabilitation strategy. However, before an effective health surveillance strategy can be developed, medical and coaching staff require a detailed knowledge of the causes of injury within their own clubs and within other clubs for comparative purposes. Few prospective studies have been carried out that both involve senior professional footballers and provide the level of detailed information on injuries that is required for this purpose. ${ }^{10-12}$

The aim of this work was to establish, using a prospective epidemiological study, the causes of occupational injury to players in four English professional football clubs during competition and training over a period of three years. It is expected that prospective epidemiological studies of this type can provide the necessary benchmark data for establishing effective injury prevention and rehabilitation programmes as part of a proactive risk management strategy.

\section{Methods}

Player injuries were prospectively recorded over the period November 1994 to May 1997 at four English professional football clubs. All professional players at these clubs were included in the study together with youth players from two of the clubs. Each injury was diagnosed by the clubs' senior physiotherapists, who were qualified to either Chartered status or FA Diploma level. The senior physiotherapist at each of the four clubs recorded their injury data on a specific injury report form designed for this study (fig 1). The data recorded for each injury included information related to the date and place of occurrence, player identification, type of activity, injury description, and extrinsic playing factors. A recordable injury was defined as one received during competition or training that prevented the injured player from participating in competition or normal training for at least one day, not including the day of the injury. Absence arising from sickness or other general medical conditions, which required examination by a player's own general practitioner, was not included in the study. The severity of each
Accepted for publication 11 February 1999 
LOCATION:

1. Date of injury:

2. Venue: ( ) home; ( ) away; ( ) training ground; ( ) other (specify)

3. Playing surface type: ( ) grass; ( ) track; ( ) indoor; ( ) all-weather; ( ) artificial.

4. Playing surface condition: ( ) dry; ( ) frozen; ( ) wet/muddy; ( ) N/A

PLAYER IDENTIFICATION:

5. Squad number:

6. Injury number:

7. Playing position when injured: ( ) GK; ( ) defence; ( ) midfield; ( ) attack; ( ) N/A

INJURY DESCRIPTION:

8. Nature of injury: ( ) abrasion; ( ) blisters; ( ) concussion; ( ) contusion; ( ) dislocation; ( ) fracture; ( ) laceration; ( ) overuse; ( ) sprain; ( ) strain; ( ) other (specify)

9. Anatomical location: ( ) head; ( ) face; ( ) neck; ( ) shoulder; ( ) elbow; ( ) forearm; ( ) wrist; ( ) hand; ( ) chest; ( ) back; ( ) abdominal; ( ) hip; ( ) groin; ( ) thigh; ( ) knee; ( ) lower leg ( ) ankle; ( ) foot; ( ) other (specify)

10. Injured body side: ( ) dominant; ( ) non-dominant; ( ) N/A

11. Removal from play: ( ) immediately; ( ) later; ( ) not at all

12. Severity of injury: ( ) slight; ( ) minor; ( ) moderate; ( ) major

13. Re-injury: ( ) yes; ( ) no; ( ) unknown

14. Medical classification of injury: Specify -

INJURY DESCRIPTORS:

15. Time of injury (minutes): First half - ( ) $0-15$; ( ) 15-30; ( ) 30-45; Second half - ( ) 45-60; ( ) 60-75; ( ) 75-90; ( ) N/A

16. Activity: ( ) competitive game; 11-sided practice game; ( ) small-sided practice game; ( ) exercise; ( ) drill; ( ) other (specify)

17. Injury mechanism: ( ) tackling; ( ) tackled; ( ) running; ( ) falling; ( ) shooting; ( ) dribbling; ( ) jumping; ( ) landing; ( ) heading; ( ) turning; ( ) collision; ( ) overuse; ( ) other (specify)

18. Refereeing decision: ( ) free-kick for; ( ) free-kick against; ( ) no free-kick; ( ) N/A

19. Playing equipment: ( ) studs; ( ) moulded; ( ) flats; ( ) running shoes; ( ) shin pads worn; ( ) shin pads not worn

Figure 1 Injury report format.

injury was defined by the length of time that a player was absent from training or competition: slight, one to three days; minor, four to seven days; moderate, one to four weeks; major, more than four weeks. The specific days when players were unavailable through injury were recorded by the physiotherapist on a separate $\log$ sheet. The categories designated as minor, moderate, and major correspond to injuries that are reportable in the United Kingdom under the Reporting of Injuries, Diseases and Dangerous Occurrences Regulations ${ }^{13}$ (RIDDOR).

In addition to the data directly related to players' injuries, the date of every competitive game played at each club by the professional and, where applicable, youth players was recorded. The number of hours that players were exposed to risk during competition was calculated for each club by assuming that 11 players from the club were on the pitch at all times during each match and that each match lasted for 100 minutes (45 minutes standard play plus five minutes extra time each half). The number of hours that players were at risk during training was estimated for each club from the number of players attending training sessions and the typical daily training pro-

Table 1 Observational data for clubs

\begin{tabular}{|c|c|c|c|c|c|c|}
\hline \multirow{2}{*}{$\begin{array}{l}\text { Club } \\
\text { (Division) }\end{array}$} & \multirow{2}{*}{$\begin{array}{l}\text { Observation } \\
\text { period (weeks) }\end{array}$} & \multicolumn{2}{|c|}{$\begin{array}{l}\text { Average number of } \\
\text { players }\end{array}$} & \multicolumn{2}{|c|}{$\begin{array}{l}\text { Number of matches } \\
\text { played }\end{array}$} & \multirow{2}{*}{$\begin{array}{l}\text { Team training } \\
\text { (hours) }\end{array}$} \\
\hline & & Pro & Youth & Pro & Youth & \\
\hline $\mathrm{A}(1 \mathrm{st} / \mathrm{Pr})$ & 82 & 30 & 14 & 156 & 75 & 451 \\
\hline $\mathrm{B}(1 \mathrm{st} / 2 \mathrm{nd})$ & 114 & 24 & $\star$ & 242 & $\star$ & 513 \\
\hline $\mathrm{C}(1 \mathrm{st})$ & 106 & 26 & $\star$ & 220 & $\star$ & 636 \\
\hline $\mathrm{D}(\mathrm{Pr})$ & 105 & 28 & 16 & 205 & 85 & 473 \\
\hline Total & 407 & 108 & 30 & 823 & 160 & 2073 \\
\hline
\end{tabular}

*Youth players not included in study.

Pr, premier; Pro, professional. grammes employed by each club. Injury frequency rates (IFRs) were then calculated for each club as the number of injuries per 1000 hours of competition and/or training.

During the study, each player was assigned a unique code number so that their identity was known only to their own physiotherapist. Data were stored and analysed using the computer based software SPSS (Chicago, Illinois, USA). In performing statistical analyses the $\chi^{2}$ significance test was used to investigate differences between variables, and statistical significance was accepted at the $95 \%$ confidence level, unless stated otherwise.

\section{Results}

Table 1 summarises the number of weeks, number of players, number of matches, and estimated number of team training hours covered at each club during the study. The observation period included a total of 983 competitive matches and an estimated 2073 hours of team training. During the period of study, a total of 744 injuries were recorded for professional and youth players resulting from competition and training (table 2). During each full

Table 2 Number of injuries sustained at each football club during competition and training

\begin{tabular}{lrrrrr}
\hline & \multicolumn{3}{l}{ Number of injuries } & & \\
\cline { 2 - 3 } & \multicolumn{2}{l}{ Competition } & & \multicolumn{2}{l}{ Training } \\
\cline { 2 - 3 } \cline { 5 - 6 } Club & Pro & Youth & & Pro & Youth \\
\hline A & 93 & 26 & & 43 & 18 \\
B & 83 & $\star$ & & 45 & $\star$ \\
C & 145 & $\star$ & & 42 & $\star$ \\
D & 70 & 83 & & 57 & 39 \\
Total & 391 & 109 & & 187 & 57 \\
\hline
\end{tabular}

*Youth players not included in study.

Pro, professional. 


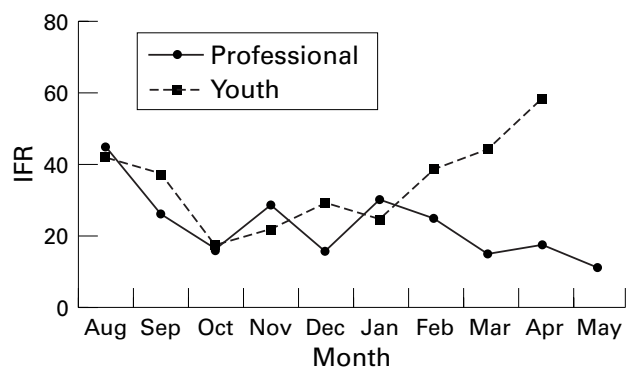

Figure 2 Average injury frequency rates (IFRs) per month for footballers in competition.

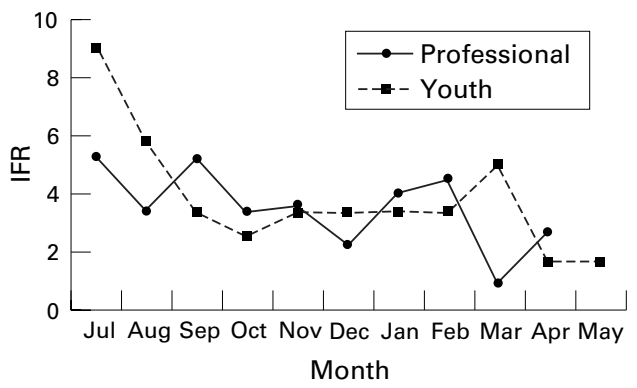

Figure 3 Average injury frequency rates (IFRs) per month for footballers in training.

season analysed, the percentage of players from each club that sustained at least one recordable injury ranged from 86 to 100 . Some $68 \%$ of all injuries to professional players and $66 \%$ of all injuries to youth players occurred during competition.

The overall IFR for all players at all clubs over the three seasons of competition and training was 8.5 injuries/ 1000 hours. The overall IFR calculated for competition $(27.7 ; 25.9$ for professional and 37.2 for youth players) was significantly $(p<0.01)$ higher than that calculated for training $(3.5 ; 3.4$ for professional and 4.1 for youth players). Figure 2 shows the average IFRs per month for injuries sustained during competition, and fig 3 shows those for injuries sustained during training, for professional and youth players for the two full seasons monitored (1995/96 and 1996/97). The average number of days absence per injury was 14.6, which was composed of 15.2 days for competition (15.2 for both professional and youth players) and 13.4 days for training (13.6 for professional and 13.0 for youth players).

Figure 4 shows an analysis of the match injuries with respect to their time of occurrence for professional and youth players. Significantly

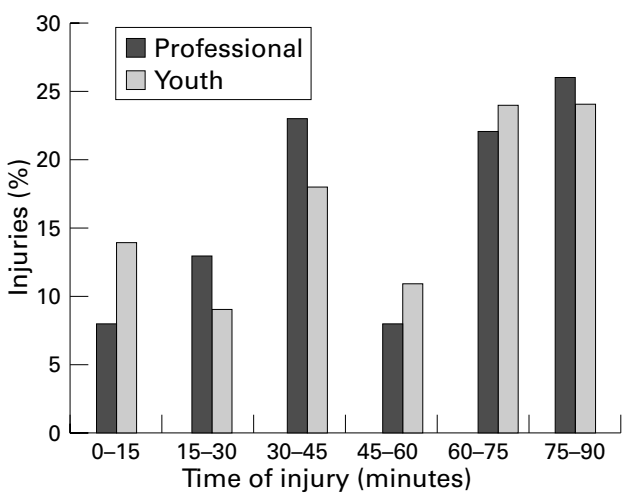

Figure 4 Time of occurrence of injuries in football matches.

$(\mathrm{p}<0.01)$ more injuries were observed during the final 15 minutes of the first half and the final 30 minutes of the second half for both professional and youth players. There were also significantly $(p<0.01)$ more injuries recorded in the second half compared with the first half of matches for both professional (56\% v 44\%) and youth ( $59 \% v 41 \%)$ players.

Table 3 gives the nature of the injuries sustained during competition and training for professional and youth players. A total of $41 \%$ of all injuries were classified as muscular strains, which represented twice the level of injuries classified as sprains $(20 \%)$ or contusions $(20 \%)$, which were the two next most common injuries. Injuries grouped under "other" include abrasions, concussions, dislocations, disc derangements, and meniscal tears; however, individual categories within this group amounted to less than $2 \%$ of all injuries.

Dominant body side injuries (52.3\%) were significantly $(\mathrm{p}<0.01)$ greater than nondominant side injuries (38.7\%); this significant difference was present for professional and youth players and for competition and training. The remaining $9 \%$ of injuries were nonassigned injuries to the head or torso. Some $86 \%$ of all injuries sustained by players were in the lower extremities (table 4). A total of $81 \%$ of all thigh injuries were muscular strains, and significantly $(p<0.01)$ more injuries were observed to the posterior than to the anterior aspect during competition but this difference was not observed during training. Ligament sprains accounted for $76 \%$ of all ankle injuries

Table 3 Nature of injuries sustained during competition and training

\begin{tabular}{|c|c|c|c|c|c|c|c|c|c|c|}
\hline \multirow[b]{3}{*}{ Nature of injury } & \multirow{2}{*}{\multicolumn{2}{|c|}{$\begin{array}{l}\text { All injuries } \\
\text { Pro }+ \text { youth }\end{array}$}} & \multicolumn{4}{|c|}{ Match injuries } & \multicolumn{4}{|c|}{ Training injuries } \\
\hline & & & \multicolumn{2}{|l|}{ Pro } & \multicolumn{2}{|c|}{ Youth } & \multicolumn{2}{|l|}{ Pro } & \multicolumn{2}{|c|}{ Youth } \\
\hline & No & $\%$ & No & $\%$ & No & $\%$ & No & $\%$ & No & $\%$ \\
\hline Strain & 305 & 41 & 145 & 37 & 30 & 28 & 100 & 53 & 30 & 53 \\
\hline Sprain & 149 & 20 & 83 & 21 & 22 & 20 & 33 & 18 & 11 & 19 \\
\hline Contusion & 148 & 20 & 94 & 24 & 35 & 32 & 10 & 5 & 9 & 16 \\
\hline Overuse & 31 & 4 & 20 & 5 & 1 & 1 & 9 & 5 & 1 & 2 \\
\hline Fracture & 29 & 4 & 15 & 4 & 6 & 6 & 7 & 4 & 1 & 2 \\
\hline Laceration & 15 & 2 & 8 & 2 & 5 & 5 & 2 & 1 & 0 & 0 \\
\hline Other & 67 & 9 & 26 & 7 & 10 & 9 & 26 & 14 & 5 & 9 \\
\hline Total $^{\star}$ & 744 & 100 & 391 & 100 & 109 & 101 & 187 & 100 & 57 & 101 \\
\hline
\end{tabular}

*Percentage totals may be subject to rounding errors associated with individual components. 
Table 4 Locations of injuries sustained during competition and training

\begin{tabular}{|c|c|c|c|c|c|c|c|c|c|c|}
\hline \multirow[b]{3}{*}{ Location of injury } & \multirow{2}{*}{\multicolumn{2}{|c|}{$\frac{\text { All injuries }}{\text { Pro }+ \text { youth }}$}} & \multicolumn{4}{|c|}{ Match injuries } & \multicolumn{4}{|c|}{ Training injuries } \\
\hline & & & \multicolumn{2}{|l|}{ Pro } & \multicolumn{2}{|c|}{ Youth } & \multicolumn{2}{|l|}{ Pro } & \multicolumn{2}{|c|}{ Youth } \\
\hline & No & $\%$ & No & $\%$ & No & $\%$ & No & $\%$ & No & $\%$ \\
\hline Thigh & 171 & 23 & 89 & 23 & 23 & 21 & 43 & 23 & 16 & 28 \\
\hline Ankle & 125 & 17 & 69 & 18 & 18 & 17 & 28 & 15 & 10 & 18 \\
\hline Knee & 103 & 14 & 59 & 15 & 11 & 10 & 27 & 14 & 6 & 11 \\
\hline Lower leg & 95 & 13 & 47 & 12 & 10 & 9 & 33 & 18 & 5 & 9 \\
\hline Groin & 82 & 11 & 42 & 11 & 11 & 10 & 20 & 11 & 9 & 16 \\
\hline Torso & 52 & 7 & 25 & 6 & 3 & 3 & 19 & 10 & 5 & 9 \\
\hline Foot & 45 & 6 & 28 & 7 & 10 & 9 & 4 & 2 & 3 & 5 \\
\hline Head/face/neck & 28 & 4 & 13 & 3 & 12 & 11 & 1 & 1 & 2 & 4 \\
\hline Upper extremity & 22 & 3 & 9 & 2 & 6 & 6 & 7 & 4 & 0 & 0 \\
\hline Hip & 21 & 3 & 10 & 3 & 5 & 5 & 5 & 3 & 1 & 2 \\
\hline Total $^{\star}$ & 744 & 101 & 391 & 100 & 109 & 101 & 187 & 101 & 57 & 102 \\
\hline
\end{tabular}

*Percentage totals may be subject to rounding errors associated with individual components. Pro, professional.

Table 5 Mechanisms of injuries sustained during competition and training

\begin{tabular}{|c|c|c|c|c|c|c|c|c|c|c|}
\hline \multirow[b]{3}{*}{ Mechanism } & \multirow{2}{*}{\multicolumn{2}{|c|}{$\frac{\text { All injuries }}{\text { Pro }+ \text { youth }}$}} & \multicolumn{4}{|c|}{ Match injuries } & \multicolumn{4}{|c|}{ Training injuries } \\
\hline & & & \multicolumn{2}{|l|}{ Pro } & \multicolumn{2}{|c|}{ Youth } & \multicolumn{2}{|l|}{ Pro } & \multicolumn{2}{|c|}{ Youth } \\
\hline & No & $\%$ & No & $\%$ & No & $\%$ & No & $\%$ & No & $\%$ \\
\hline Tackled & 171 & 23 & 110 & 28 & 32 & 29 & 18 & 10 & 11 & 19 \\
\hline Running & 141 & 19 & 69 & 18 & 8 & 7 & 57 & 30 & 7 & 12 \\
\hline Tackling & 104 & 14 & 68 & 17 & 19 & 17 & 10 & 5 & 7 & 12 \\
\hline Shooting & 74 & 10 & 22 & 6 & 9 & 8 & 31 & 17 & 12 & 21 \\
\hline Turning & 60 & 8 & 21 & 5 & 3 & 3 & 25 & 13 & 11 & 19 \\
\hline Overuse & 60 & 8 & 40 & 10 & 6 & 6 & 12 & 6 & 2 & 4 \\
\hline Landing & 37 & 5 & 20 & 5 & 7 & 6 & 9 & 5 & 1 & 2 \\
\hline Collision & 30 & 4 & 14 & 4 & 13 & 12 & 1 & 1 & 2 & 4 \\
\hline Heading & 15 & 2 & 9 & 2 & 4 & 4 & 2 & 1 & 0 & 0 \\
\hline Jumping & 15 & 2 & 8 & 2 & 0 & 0 & 6 & 3 & 1 & 2 \\
\hline Other & 37 & 5 & 10 & 3 & 8 & 7 & 16 & 9 & 3 & 5 \\
\hline Total* & 744 & 100 & 391 & 100 & 109 & 99 & 187 & 100 & 57 & 100 \\
\hline
\end{tabular}

*Percentage totals may be subject to rounding errors associated with individual components.

Pro, professional.

and $45 \%$ of all knee injuries, of which $76 \%$ were to the medial collateral ligament.

A look at the injury mechanisms, summarised in table 5 , shows that fewer injuries were caused by contact mechanisms ( $41 \%$; tackled, tackling, collision) than by non-contact mechanisms $(59 \%)$. A consideration of the severity of all the injuries recorded (table 6) shows that $84 \%$ of injuries (minor, moderate, and major) would be regarded as reportable injuries under RIDDOR. ${ }^{13}$ Of the 405 match injuries for which a refereeing decision (foul or non-foul) was recorded, $18 \%$ were the result of a foul, $86 \%$ of which were caused by the opponent. Based on the severity of match injuries, there were no significant differences in the severity of the injury depending on whether or not a foul, for or against the player, was committed at the time of the injury.

Reinjuries accounted for $22 \%$ of all injuries sustained during the study period (table 7), and $76 \%$ of the 164 reinjuries documented were strains $(49 \%)$ or sprains $(27 \%)$ (table 8$)$; of the 32 recurrent thigh strains, $82 \%$ were to the posterior aspect. From the observed frequency of reinjury, it was found that the incidence of recurrent ankle sprains was significantly higher than the average $(32 \% v$ $22 \%)$. There was also a tendency for the reinjuries to be more severe than other injuries; however, no statistical significance could be attached to this result.

\section{Discussion}

Definitions used in this work for "recordable injury" and "injury severity" 2615 follow those used previously. Inclusion of the injury severity category "slight" (one to three days) also enables the number of injuries that are defined as reportable under RIDDOR ${ }^{13}$ to be identified. The results obtained in the present study (744 injuries) are compared primarily

Table 6 Severity of injuries sustained during competition and training

\begin{tabular}{|c|c|c|c|c|c|c|c|c|c|c|}
\hline \multirow[b]{3}{*}{ Nature of injury } & \multirow{2}{*}{\multicolumn{2}{|c|}{$\begin{array}{l}\text { All injuries } \\
\text { Pro }+ \text { youth }\end{array}$}} & \multicolumn{4}{|c|}{ Match injuries } & \multicolumn{4}{|c|}{ Training injuries } \\
\hline & & & \multicolumn{2}{|l|}{ Pro } & \multicolumn{2}{|c|}{ Youth } & \multicolumn{2}{|l|}{ Pro } & \multicolumn{2}{|c|}{ Youth } \\
\hline & No & $\%$ & No & $\%$ & No & $\%$ & No & $\%$ & No & $\%$ \\
\hline Slight & 119 & 16 & 75 & 19 & 18 & 17 & 20 & 11 & 6 & 11 \\
\hline Minor & 260 & 35 & 133 & 34 & 29 & 27 & 75 & 40 & 23 & 40 \\
\hline Moderate & 283 & 38 & 140 & 36 & 47 & 43 & 74 & 40 & 22 & 39 \\
\hline Major & 82 & 11 & 43 & 11 & 15 & 14 & 18 & 10 & 6 & 11 \\
\hline Total $^{\star}$ & 744 & 100 & 391 & 100 & 109 & 101 & 187 & 101 & 57 & 101 \\
\hline
\end{tabular}

$\star$ Percentage totals may be subject to rounding errors associated with individual components. 
Table 7 Recurrent injuries sustained during competition and training

\begin{tabular}{|c|c|c|c|c|c|c|c|c|c|c|}
\hline \multirow[b]{3}{*}{ Injury type } & \multirow{2}{*}{\multicolumn{2}{|c|}{$\frac{\text { All injuries }}{\text { Pro }+ \text { youth }}$}} & \multicolumn{4}{|c|}{ Match injuries } & \multicolumn{4}{|c|}{ Training injuries } \\
\hline & & & \multicolumn{2}{|l|}{ Pro } & \multicolumn{2}{|c|}{ Youth } & \multicolumn{2}{|l|}{ Pro } & \multicolumn{2}{|c|}{ Youth } \\
\hline & No & $\%$ & No & $\%$ & No & $\%$ & No & $\%$ & No & $\%$ \\
\hline Reinjury & 164 & 22 & 86 & 22 & 11 & 10 & 53 & 28 & 14 & 25 \\
\hline New injury & 565 & 76 & 292 & 75 & 98 & 90 & 132 & 71 & 43 & 75 \\
\hline Unknown & 15 & 2 & 13 & 3 & 0 & 0 & 2 & 1 & 0 & 0 \\
\hline Total $^{\star}$ & 744 & 100 & 391 & 100 & 109 & 100 & 187 & 100 & 57 & 100 \\
\hline
\end{tabular}

$\star$ Percentage totals may be subject to rounding errors associated with individual components. Pro, professional.

Table 8 Anatomical location of recurrent strain and sprain injuries

\begin{tabular}{|c|c|c|c|c|c|c|c|c|}
\hline \multirow[b]{3}{*}{ Location of injury } & \multicolumn{4}{|c|}{ Strains } & \multicolumn{4}{|c|}{ Sprains } \\
\hline & \multicolumn{2}{|l|}{ Pro } & \multicolumn{2}{|c|}{ Youth } & \multicolumn{2}{|l|}{ Pro } & \multicolumn{2}{|c|}{ Youth } \\
\hline & No & $\%$ & $\mathrm{No}$ & $\%$ & No & $\%$ & No & $\%$ \\
\hline Thigh & 26 & 37 & 6 & 60 & 0 & 0 & 0 & 0 \\
\hline Ankle & 0 & 0 & 0 & 0 & 23 & 62 & 8 & 100 \\
\hline Groin & 22 & 31 & 2 & 20 & 0 & 0 & 0 & 0 \\
\hline Lower leg & 16 & 23 & 1 & 10 & 0 & 0 & 0 & 0 \\
\hline Knee & 0 & 0 & 0 & 0 & 11 & 30 & 0 & 0 \\
\hline Others & 6 & 9 & 1 & 10 & 3 & 8 & 0 & 0 \\
\hline Total $^{\star}$ & 70 & 100 & 10 & 100 & 37 & 100 & 8 & 100 \\
\hline
\end{tabular}

$\star$ Percentage totals may be subject to rounding errors associated with individual components.

Pro, professional.

with prospective studies reported by Lewin ${ }^{11}$ for an English First Division team over the 1987/88 season (66 injuries) and McGregor and $\mathrm{Rae}^{12}$ for a Scottish Premier League team over the three seasons 1990 to 1993 (94 injuries).

GENERAL ASSESSMENT

The high proportion (86-100\%) of players injured at each club during each season compares with previous values reported for UK clubs of $91 \%{ }^{11}$ and $71-79 \%{ }^{12}$ and confirms the high risks to which players are exposed. The proportion $(67 \%)$ of injuries sustained by players during competition supports previously reported values of $66 \%{ }^{11}$ and $78 \% .{ }^{12}$ However, this value also shows that a high proportion of injuries are still sustained during training, when players are generally under supervision and may reasonably expect to be at a significantly lower level of risk. Only $18 \%$ of all injuries caused during competition resulted from a foul, which compares closely with previous results ${ }^{3616}$ of $15-29 \%$. In those situations where a foul was committed, $86 \%$ of injuries were caused by the opponent compared with reported values of $97 \%{ }^{7}$ and $76 \% .{ }^{17}$ Foul play by opponents during competition therefore caused only about $10 \%$ of all injuries to players, indicating that, in general, violations by players do not represent a major cause of injury.

The IFR of 27.7 obtained for competition (25.9 for professional and 37.2 for youth players) compares with previously reported values for UK football, recalculated on an equivalent basis, for competition of 23.8 for professional players $^{12}$ and 14.5 for professional and youth players. ${ }^{11}$ Other IFRs reported for competition $^{16715}$ and training ${ }^{1}$ have ranged from 7 to 19 . These results confirm a previous report ${ }^{18}$ that the risk of injury in professional football is around 1000 times higher than that observed in other industrial occupations-for example, construction and mining (0.02 injuries/1000 hours) - which are generally regarded as high risk. ${ }^{19}$ The results reported for English football are also only slightly lower than those ${ }^{2021}$ for rugby league in England (28 to 50 injuries/1000 hours), which is a contact sport.

The severity of an injury was categorised by the length of time players were absent from competition or training. Under UK health and safety legislation, ${ }^{13}$ any injury at work resulting in an absence from work for over three days must be reported to the appropriate authority; therefore $84 \%$ of the injuries documented in this study would be classified as reportable injuries. Comparisons of injury severity between studies are often difficult, owing to variations in the definitions and sample populations used; however, Ekstrand and Gillquist ${ }^{22}$ reported the same level $(11 \%)$ of injury resulting in absences from competition and training of over four weeks as that found here. No significant differences were observed in the severity of injuries based on the average number of days lost per injury between professional and youth players or between competition and training. The overall result obtained of 14.6 days lost per injury is lower than previously reported for competition and training (19.9 $9^{11}$ and $27.1^{12}$ days respectively).

Consideration of the time during a match at which injury occurs highlights the final 15 minutes as the period of greatest risk of injury in each half (fig 4). While the significantly higher level of injury found in the second half of matches supports the results obtained by Sandelin et $a l^{2}$ and Arnason et $a l^{23}$ others have reported that more injuries occur in the first half of matches. ${ }^{17}$ The role of muscle fatigue has previously been discussed and identified as a factor in injury causation, ${ }^{24}$ and this could partly explain the greater risk of injury 
observed during the final 15 minutes of each half. If this is the case, the importance placed on players' endurance training and carbohydrate intake ${ }^{25}$ is further increased.

The incidence of injury has previously been reported to vary over different periods of the playing season, ${ }^{1} 21011$ with peak injury rates reported to occur after preseason training and mid-season breaks and during match intensive periods. However, these previous reports have not accounted for variations in the intensity of competition experienced by players over a season, and these variations may therefore simply be a function of the number of games played at these times; by presenting results as IFRs, this factor has been taken into account. During competition (fig 2), the IFR for professional players is over 40 at the start of the season but falls progressively over the season to below 20 . For youth players, the IFR is also over 40 at the start of the season but falls to around 20 from August to October and then progressively increases to over 60 by the end of the season. However, during training (fig 3), there is little difference over the season between the IFRs for professional and youth players, with values decreasing steadily after the start of season.

White $e t a l^{26}$ reported that there was a loss of fitness during the closed season and that this had a potential impact on players' performance. It is possible that this loss of fitness during the closed season also renders the players less able to withstand the stresses associated with preseason training and early season competition, which leads to a higher propensity for injury. Consideration should therefore be given to the level of closed season training, the content of preseason training, and the physiological testing of players to enable more accurate judgments to be made about the progress of their fitness during early season. The increasing level of injury observed for youth players towards the end of the season supports the concerns expressed by the Football Association ${ }^{27}$ over the total number of games in which young players compete over the course of a season. It is expected therefore that the establishment of the football academies for young players at professional clubs, together with the standards set by the Football Association relating to the maximum number of matches played by youth players in a season, will go a long way towards addressing this issue.

\section{NATURE OF INJURIES}

Strains, sprains, and contusions represented over $75 \%$ of all injuries to professional and youth players during both competition and training (table 3 ). These results support previous research, ${ }^{14611} 121528$ although the overall level of muscular strains ( $41 \%$ ) reported in this study dominates the three injury categories. The high proportion of strains observed during competition $(35 \%)$ and in training $(53 \%)$ is a cause for concern, as this level is higher than that reported for European teams. ${ }^{101522}$ Ekstrand ${ }^{1}$ has discussed the relation between muscle tightness and a player's propensity for muscle strains and shown the beneficial effects of warm up and cool down programmes for reducing muscle tightness and the number of muscle strains. It is possible that the attention paid to general body conditioning - for example, through strength and flexibility training and warm ups and cool downs ${ }^{29}$-is less than that found at clubs in Europe, thus making players at English clubs more liable to muscle strains. This view is also supported by the general lack of awareness found among players at the clubs in the present study of the benefits of injury prevention strategies. ${ }^{25}$

\section{LOCATION OF INJURIES}

The predominance of dominant side injuries in competition and training confirms the results of Ekstrand and Gillquist, ${ }^{17}$ who suggested ${ }^{30}$ that the dominant side was exposed to enhanced levels of risk during jumping, kicking, and tackling. A total of $86 \%$ of all injuries in this study were located in the lower extremity, a level similar to that reported elsewhere. ${ }^{12} 1731$ The most common injury locations were the thigh $(23 \%)$, ankle $(17 \%)$, and knee $(14 \%)$, whereas the ankle and knee have previously been reported as the most common injury locations. ${ }^{16}{ }^{15}{ }^{28} \mathrm{McGregor}$ and $\mathrm{Rae}^{12}$ also reported a higher level (45\%) of injury to the thigh than other locations. The high number of strains recorded reflects the level of thigh injuries observed, as $81 \%$ of all thigh injuries were muscular strains. Strains to the anterior and posterior aspects of the thigh have previously been reported to be common injuries ${ }^{161528}$; in this study significantly $(\mathrm{p}<0.01)$ more thigh strains $(64 \%)$ were to the posterior rather than the anterior aspect. This could be attributed to a lack of attention paid to the hamstring muscle group, where strength imbalances have been reported ${ }^{30}$ between the agonist and antagonist muscle groups. Differences between strains to the posterior and anterior aspect of the thigh were not found in training, possibly because of the greater proportion of anterior thigh strains occurring in training than competition $(\mathrm{p}<0.01)$. This is possibly linked to the significantly $(p<0.01)$ greater proportion of injuries arising from shooting during training compared with competition (table 5).

MECHANISM OF INJURIES

Player to player contact injury mechanisms (41\%; table 5) were similar to levels reported previously. ${ }^{10}$ These injury mechanisms $(\mathrm{p}<0.01)$, together with injuries arising from heading $(p<0.05)$, were significantly greater during competition than training, as might be expected. Injuries occurring without player to player contact, however, were high, with running, shooting, turning, overuse, and jumping causing $47 \%$ of all injuries. The proportions of injuries attributable to running, shooting, and turning were all significantly $(p<0.01)$ greater during training than in competition; Ekstrand and Gillquist ${ }^{17}$ also identified running and turning as the major causes of non-contact injuries. Non-contact injury mechanisms have been reported to be the 
cause of most muscle strains, with strains to the rectus femoris mainly occurring during kicking and strains to the hamstrings or gastrocnemius during sprinting. ${ }^{10}$

RECURRENCE OF INJURIES

Inadequate rehabilitation after an injury has previously been reported as the cause of a high percentage of reinjuries by Ekstrand and Gillquist ${ }^{22}(17 \%)$ and Nielsen and $\mathrm{Yde}^{6}(25 \%)$. In the present study, $22 \%$ of all injuries were reported as reinjuries (table 7), and it is believed that this is an underestimate of the overall problem as only injuries of the same type occurring at the same location were classed as reinjury. The level of reinjury during competition was significantly higher for professional players $(22 \%)$ than youth players $(10 \%)$, but the level of reinjury during training was significantly higher than in competition, which may reflect the level of reinjury occurring during the rehabilitation process. Lysens ${ }^{32}$ reported that $30 \%$ of muscular strains and ligament sprains were reinjuries of the same type and at the same location, which compares closely with the value obtained from the current data $(27 \%)$. Of all reinjuries that were reported in the current research (table 8), 76\% were either strains, predominantly to the lower leg, thigh, and groin, or sprains, to the ankle and knee; these types of injury have previously been reported to have the highest risk of reinjury. ${ }^{623233}$ Some $32 \%$ of ankle sprains were reinjuries; Ekstrand and Gillquist ${ }^{17}$ suggested that the level of this type of injury could be reduced by using active treatment of acute ankle injuries and the use of prophylactic taping. For players with a history of ankle injuries, the use of ankle disk training has been reported to be the best means of preventing recurrent sprains by reducing functional instability. ${ }^{34}$

CONCLUSIONS

The overall level of injury to professional footballers has been confirmed as being around 1000 times higher than that foundin other industrial occupations more traditionally regarded as high risk. The risk of injury in English football, however, is only slightly lower than that found in English rugby league. In particular, the increasing IFRs observed for youth players as the season progresses emphasises the importance of controlling the risk levels to young players caused by excessive exposure to competition. Unlike in other occupations, where noncompliance with work procedures causes a high proportion of injuries, ${ }^{35}$ only $12 \%$ of injuries to footballers involved a breach of the laws of the game. However, with $41 \%$ of all injuries involving player to player contact, questions can be raised about whether referees are effectively implementing the existing laws of the game or whether the nature of allowable player to player contact should be reviewed.

The high level of muscle strains observed, particularly during training, increases the importance of implementing effective fitness training programmes and in particular warming up and cooling down procedures for players. The number of reinjuries observed and the tendency for these injuries to be more severe suggests that rehabilitation programmes used at clubs may not be adequate. There is a strong argument for the introduction of rehabilitation programmes based on the achievement of fitness targets at each stage of recovery and before a return to competition. Benchmarking players' fitness and performance levels to provide these rehabilitation targets would facilitate the process and also enable comparisons of recovery rates to be made between clubs with significantly different injury rates.

1 Ekstrand J. Soccer injuries and their prevention. Linkoping, Sweden: Linkoping University Medical Dissertations, No. 130, 1982.

2 Sandelin J, Santavirta S, Kiviluoto O. Acute soccer injuries in Finland in 1980. Br F Sports Med 1985;19:30-3.

3 Hoy K, Lindblad BE, Terkelsen CJ, et al. European soccer injuries. A prospective epidemiologic and socioeconomic injuries. A prospective epidemiologic and
study. Am f Sports Med 1992;20:318-22.

4 Albert $M$. Descriptive three year data study of outdoor and Albert M. Descriptive three year data study of outdoor and
indoor professional soccer injuries. Athletic Training 1983; 18:218-20.

5 McCarroll JR, Meaney C, Sieber JM. Profile of youth soccer injuries. Physician and Sportsmedicine 1984;12:113-17.

6 Nielsen AB, Yde J. Epidemiology and traumatology of injuries in soccer. Am $\mathcal{F}$ Sports Med 1989;17:803-7.

7 Hawkins RD, Fuller CW. An examination of the frequency and severity of injuries and incidents at three levels of professional football. Br F Sports Med 1998; 32:326-332.

8 Fuller CW. Implications of health and safety legislation for the professional sportsperson. Br F Sports Med 1995;29. $5-9$.

9 Fuller CW, Hawkins RD. Developing a health surveillance strategy for professional footballers in compliance with UK health and safety legislation. Br f Sports Med 1997;31:14850 .

10 Anglietti P, Zaccherotti G, De Biase P, et al. Injuries in soccer: mechanism and epidemiology. In: Renstrom PAFH, ed. Clinical practice of sports injury prevention and care. Oxford: Blackwell Scientific Publications, 1994: $277-84$

11 Lewin G. The incidence of injury in an English professional soccer club during one competitive season. Physiotherapy 1989;75:601-5

$12 \mathrm{McGregor}$ JC, Rae A. A review of injuries to professional footballers in a premier football team (1990-93). Scott Med f 1995;40:16-18.

13 Reporting of injuries, diseases and dangerous occurrences regulations 1995. London: HMSO, 1995 (SI 1995 no 2023).

14 Council of Europe. Sport for all: sports injuries and their prevention. Oosterbeek: National Institute for Sports Health Care, 1989.

15 Engstrom B, Forssblad M, Johansson C, et al. Does a major knee injury definitely sideline an elite soccer player? $A m \mathcal{F}$ Sports Med 1990;18:101-5.

16 Jorgensen U. Epidemiology of injuries in typical Scandinavian team sports. Br $\mathcal{F}$ Sports Med 1984;18:59-63.

17 Ekstrand J, Gillquist J. Soccer injuries and their mechanisms: a prospective study. Med Sci Sports Exerc 1983;15:267-70.

18 Hawkins RD, Fuller CW. Risk assessment in professional football: an examination of accidents and incidents in the 1994 World Cup finals. Br F Sports Med 1996;30: $165-70$.

19 Health and Safety Commission. Health and safety statistics: statistical supplement to the 1996/97 annual report. London: HMSO, 1997.

20 Hodgson Phillips L, Standen PJ, Batt ME. Effects of seasonal change in rugby league on the incidence of injury. Br 7 Sports Med 1998;32:144-8.

21 Gissane C, Jennings D, White J, et al. Injury in summer rugby league football: the experience of one club. $\mathrm{Br} \mathcal{F}$ Sports Med 1998;32:149-52.

22 Ekstrand J, Gillquist J. The avoidability of soccer injuries. Int f Sports Med 1983;4:124-8

23 Arnason A, Johannsson E, Gudmundsson A, et al. Strains, sprains and contusions in Icelandic elite soccer. Med Sci Sports Exerc 1994;26:S14.

24 Lieber RL, Friden J. Selective damage of fast glycolytic muscle fibers with eccentric contraction of the rabbit tibialis anterior. Acta Physiol Scand 1988;133:587-8.

25 Hawkins RD, Fuller CW. A preliminary assessment of professional footballers' awareness of injury prevention professional footballers' awareness of in

26 White JE, Emery, TM, Kane JE, et al. Pre-season fitness profiles of professional soccer players. In: Reilly T, Lees A, profiles of professional soccer players. In: Reilly T, Lees A, Davids K, et al, eds. Scie
Spon, 1988: 164-171. 
27 Wilkinson, H. Football education for young players: a charter for quality. London: The Football Association, 1997.

28 Poulmedis P. Muscular imbalance and strains in soccer. In: van der Togt CR, Kemper ABA, Koornneef M, eds. Proceedings of the 3rd Meeting of the Council of Europe: sports injuries and their prevention. Oosterbeek: National Institute for Sports Health Care, 1988:53-7.

29 Bangsbo J. Fitness training in football: a scientific approach. Bagsvaerd: HO+Storm, 1994.

30 Ekstrand J, Gillquist J. The frequency of muscle tightness and injuries in soccer players. Am f Sports Med 1982;10 $75-8$.

31 Keller CS, Noyes FR, Buncher CR. The medical aspects of soccer injury epidemiology. Am f Sports Med 1987;15:230-7.
32 Lysens RJJ. Epidemiological study of soccer injuries in the 18 teams of the first national division of the Royal Belgium Soccer Association (RBSA) during the season 1980-1981. In: van der Togt CR, Kemper ABA, Koornneef M, eds. Proceedings of the 3rd Meeting of the Council of Europe: sports injuries and their prevention. Oosterbeek: National Institute for Sports Health Care, 1988:53-7.

33 Ekstrand J, Tropp H. The incidence of ankle sprains in soccer. Foot Ankle 1990;11:41-4.

34 Tropp H, Askling C, Gillquist J. Prevention of ankle sprains. Am $\mathcal{F}$ Sports Med 1985;13:259-62.

35 Health and Safety Executive. Human factors in industrial safety. HS (G)48. Sheffield: HSE Books, 1995.

\section{Take home message}

The risks of injury are present and accepted in all forms of sport and excerise even though the levels of risk are frequently unknown or misunderstood by many of those involved. Benchmarking current levels of risk in sport allows risk comparisons between sports and over periods of time to be made. The data presented then provide administrators, coaches, physiotherapists, commentators, and, above all, participants with the information to make informed judgments on risk acceptability in sport.

\section{Commentary}

This is a well designed prospective study examining the demographics of injuries over an average of two seasons. The data show that, as we are all aware, professional footballers are at high risk of sustaining work related injuries, although over a half of these injuries were classified as only slight or minor and the majority of these refer to muscular strains. Interestingly, the authors have also looked at IFRs, which were calculated as the number of injures per 1000 hours exposure to competition and/or training. Not surprisingly, this showed that, at the beginning of the season, the IFR was high for both senior professionals and youth players and steadily fell through the season until January and continued at a lower level for senior players through to the end of the season. Surprisingly, the IFR increases from January onwards for the youth players, and reaches its highest level at the end of the season. The authors state that this increase in the youth players is due to exposure to games, yet, by necessity, it is not due to increased exposure overall and secondly the number of games played by the youth players is considerably less overall than the senior players. It may reflect the natural selection of players who are less prone to injury making the senior grades. Quite clearly, further work is required in this area and one should not be complacent about the exposure to high intensity training and competition of young players who may not be fully skeletally mature.

G MCCANN

Glasgow 